\title{
A Comparative Investigation of Bangladesh and African Sub Continent Countries Pre-Primary Education
}

\author{
Md Mirajur Rhaman Shaoan \\ Southwest University Chongqing, China
}

\begin{abstract}
Background: Purpose of Comparative Education Research: Comparative education research helps to understand educational processes between the countries where the analysis is carried out. Mainly comparative education research helps understand other countries' education systems. It also helps to draw some lessons to improve the education system. Besides, Comparative education research, many cases may generate new knowledge and contribute to the theory. Comparative education research contributes to improving the desired aspects of the education process through three specific following ways:
\end{abstract}

1. Understanding the countries themselves

2. Using the knowledge gained from the examples of the two countries to generalize to others and contributing to the theory Understanding the countries themselves

Through the use of comparative analysis, African sub continent countries will appreciate their education program. The conditions of the educational cycle and the other essential elements of comparative education research should be described. Besides, they should also consider each other's structures and gain lessons to develop their systems. In particular, the government authority can often use comparative education research findings as evidence to identify its potential areas for improvement. They should build on others' related perspectives to adapt them to their issues to incorporate appropriate solutions.

\section{INTRODUCTION}

Using the knowledge gained from the examples of the two countries to generalize to others

$\mathrm{T}$ he comparative education analysis refers to a thorough explanation of the history and the associated phenomena between the target countries, which occur in various geographical settings. This offers a comprehensive overview of the development of generalizations about the different facets of school systems. The themes methodology starts right from the outset to tackle the specific problems of qualitative education-comparison and study. Examples and experience from the two countries in educational systems also include generalization processes that better understand one's school environment.

\section{Contributing to the theory}

Comparative education research further adds to the theory by investigating the countries' educational method to be studied.
It gives way to various views on educational realities. It broadens existing knowledge and compares aspects that include new dimensions and lenses that make the current theory more diversified.

However, this paper explains some specific aspects of preprimary education in Bangladesh. It also seeks to compare the Bangladeshi system with African sub continent countries that have been identified through comparative education. Research carried out by the United Nations Educational Scientific and Cultural Organization (UNESCO) and published the findings as 'Education for All (EFA) Global Monitoring Report (2015) provides the premise of the present study.

\section{CONCEPT OF PRE-PRIMARY EDUCATION: INTERNATIONAL PERSPECTIVES}

Pre-primary education is considered the basis for the preparatory phase of formal education that provides the necessary support to children for their proper growth and development (DPEd, 2013; Barnett, 2008). Pre-primary education is the basis of the preparatory phase of formal education. Globally, pre-primary education is assumed to provide the children with the requisite resources for their future growth and development. Pre-primary education aims to provide the necessary support and activities before the formal primary level of education.

It ensures their right to prepare for formal schooling by providing children with opportunities for care, survival, play, entertainment, and the basic introduction of literacy and numeracy skills. All pre-primary education approaches are focused on and defended by children and include aspects of their growth and development, both physically, emotionally and socially, that include all other related elements that ensure their holistic development (DPEd, 2013, p.85).

UNESCO (2006) points out that the purpose of pre-primary education is to help children develop the structures they need to plan for successful learning later in primary school. The Finnish National Board of Education (2010) established the critical role of pre-primary education. This seeks to encourage children's tremendous potential to progress comprehensively on the developmental dimensions of physical, psychological, financial, cognitive, emotional and other relevant influences that play a role in fostering children's growth and 
development. As the Finnish National Board of Education (FNBE) (2010) points out:

\begin{abstract}
The central role of pre-primary education is to foster favourable growth, creation and learning opportunities for children. It includes fostering and tracking physical, economic, educational, cognitive and emotional growth and avoiding any problems that might occur. It is necessary to reinforce the healthy sense of self-esteem of children through meaningful learning activities and to provide incentives for varied encounters with others (FNBE, 2010, p.5).
\end{abstract}

UNESCO (2006) points out the pre-primary education as a natural entry to early childhood provision that entails the most realistic way to approach the EFA declaration that learning begins at birth:

For the education sector, pre-primary education is a normal entry point into early childhood education. Pre-primary education is to be prioritised on the basis that it encourages the holistic development of children, that it is provided in an environment that meets the basic educational standards and that there is a gradual approach for the incorporation of younger age groups. So long as these preconditions are met, the pre-primary education system is the most prominent part sensible way for the education sector to approach the EFA declaration that learning begins at birth (UNESCO, 2006, p.3).

Pre-primary educationist a one-year-long school readiness programmed for children of $5+$ years of age to be prepared for further quality education in formal primary schools. Preprimary education ensures a smooth transition to primary education and lay the foundation for lifelong learning (Haque et al. 1, 2013; Kaul, V., 2002).Therefore, pre-primary education has already been accepted as an essential part of the government strategy for quality primary education in Bangladesh, like other developing countries worldwide (MoE, 2010). Education policy (2010) has emphasized pre-primary education as the preparatory phase of formal primary education in Bangladesh. It stresses the value of pre-primary education that generates 'an atmosphere conducive to the development of intrinsic human dispositions, such as the senses of infinite wonder, limitless enthusiasm, excitement and inexhaustible fervour that exist in the depths of the infantile psyche' (MoE, 2010, p. 11).

\section{IMPORTANCE OF PRE-PRIMARY EDUCATION}

Quality pre-primary schooling for both girls and boys has been promoted globally in the Sustainable Development Goals (SDGs). It considers that the initiative to prepare children for higher quality education in formal primary schools worldwide, particularly in developed countries, is successful (Osborn, Cutter \& Ullah, 2015; Thomas et al., 2020). Empirical data from longitudinal studies in various countries suggests that pre-primary schooling has critical beneficial impacts on children's subsequent academic and personal lives (Berlinski, Galiani\&Gertler, 2006; UNESCO, 2006).

Haque et al. (2013) point out that pre-primary education ensures a smooth transition to primary education and provides lifelong learning. Therefore, pre-primary education has been seen as a popular strategy to protect children from formal education around the world. Kaul, V. (2002) suggests that preprimary schooling has undoubtedly had a significant effect on children's future development at and above the school's primary stage. Pre-primary schooling is also reasonably necessary for the growth of small children before they reach formal school. However, pre-primary education plays an essential role in promoting children's holistic development, including their development of physical, emotional, social, and other related aspects of children's growth and development.

Pre-primary education has also positively impacted children's learning and skills growth, such as solid and enduring academic abilities, social activity, language skills, daily participation, a greater sense of responsibility, improved vocabulary, and decreased grade duplication in the high school curriculum. Consequently, pre-school programs grow children with solid language and communication abilities with a fundamental awareness of early-school reading and numeracy skills that allow them for improved academic success in primary schools (Card and Krueger 1992; Sammons et al. 2008).UNESCO (2006) stresses the value of pre-primary education as :

Pre-primary education, though short it can be, will encourage the comprehensive growth of infants. Emphasis should be placed on well-balanced development. Health, safety, a healthy and secure atmosphere and outreach to parents and families would not be of any less value to the education and treatment of pre-primary age children UNESCO, 2006, p.3.

Comparative research in different countries has shown that well-designed pre-school education programs produce longterm improvements in school success factors, including higher achievement test scores, lower grade repeat rates, and higher education achievement (Barnett, 2008). Pre-primary education contributes to the achievement of primary education goals later in life by establishing quality learning skills in early childhood.

Pre-primary Education in Bangladesh

Pre-primary education has been accepted as an essential part of the government strategy for quality primary education in Bangladesh (MoE, 2010). Education policy (2010) has emphasized pre-primary education as the preparatory phase of formal primary education in Bangladesh. The government of Bangladesh launched the pre-primary education initiative, under Primary Education Development Programmed _ II 
(PEDP II), by introducing pre-primary lessons, prevalently referred to as "kids program"(DPE, 2006).

The government of Bangladesh has already approved its essential elements that include national curriculum for preprimary education, operational framework, development arrangement, GO-NGO cooperation instruction for entire PPE, pre-primary examine relief run of the mill and comprehensive ECCD policy. Necessary books and materials have been adopted and developed accordingly by the National Curriculum and Textbook Board (NCTB).

Bangladesh has seen a rapid rise in pre-primary education from 895,000 children enrolled in 2010 to 2.86 million five years later (Graham, 2017). To accelerate pre-primary intervention, the government and civil society partners have worked together to make one year of pre-primary education universally available in the country.

Table 1: Number of Institutes Providing Pre-primary Education by Type of Schools

\begin{tabular}{|c|c|}
\hline Type of Schools & Number of Schools \\
\hline GPS & 38,185 \\
\hline NNPS & 24,129 \\
\hline RNGPS & 98 \\
\hline NRNGPS & 1,328 \\
\hline Expt. School & 17 \\
\hline Ebtedayee Madrasha & 1,224 \\
\hline Community School & 100 \\
\hline Other School & 29,957 \\
\hline Total & 95,038 \\
\hline
\end{tabular}

Source: DPE (2015), Annual Primary School Census - 2019

Pre-primary education in Bangladesh has proliferated in a few years. The number of children in pre-primary classrooms has also been increased. The consistency of classroom practices remains a concern (Education Watch, 2013; Jahan, 2002; Daka et al., 2020). Graham (2017), a study forum, points out primary education's status, which notes that critical concerns surrounding the standard of pre-primary education should be highlighted, and scientific data on this should be identified. As it states:

Bangladesh has seen dramatic growth in pre-primary education from 895,000 children enrolled in 2010 to 2.86 million five years afterwards. Government and civil society partners have worked together to make one year of pre-primary education universally available in the country - but the quality of education delivered remains a major issue.

Comparative research evidence shows that, in some cases, teaching techniques in pre-primary classes did not differ from those in primary grades. Sports and other enjoyable games as part of the instruction are entirely missing from pre-primary classrooms. Moreover, book-based one-way deliberation has, unfortunately, been the most popular in many cases (Education Watch, 2013). Active individualized instruction in a general pre-primary classroom in the government pre-primary school in Bangladesh is also a daunting challenge for an instructor (Rashid, F., 2015).

Status of Pre-primary Education: Global Agenda

Pre-primary education is gaining prominence on the global agenda. The Millennium Development Targets did not provide any commitment to pre-primary education for girls. Nevertheless, both the Sustainable Development Goals (SDGs) and the post-2015 curriculum plan emphasize early childhood learning and especially on pre-primary education. New policies and programs are emerging at the country level that expands pre-primary education in the year or two before compulsory schooling or efforts to improve these services' quality This increased emphasis is not unexpected, considering the increasing evidence from around the world that pre-primary education attendance improves children's school preparation, adjustment to kindergarten, and early and beyond success.

The graph below (Figure 1) shows the pre-primary enrolment rates in different regions of the worlds. The charts on the last pages provide information about country-specific information.

Figure 1: Pre-primary Enrolment rates in different regions in the world

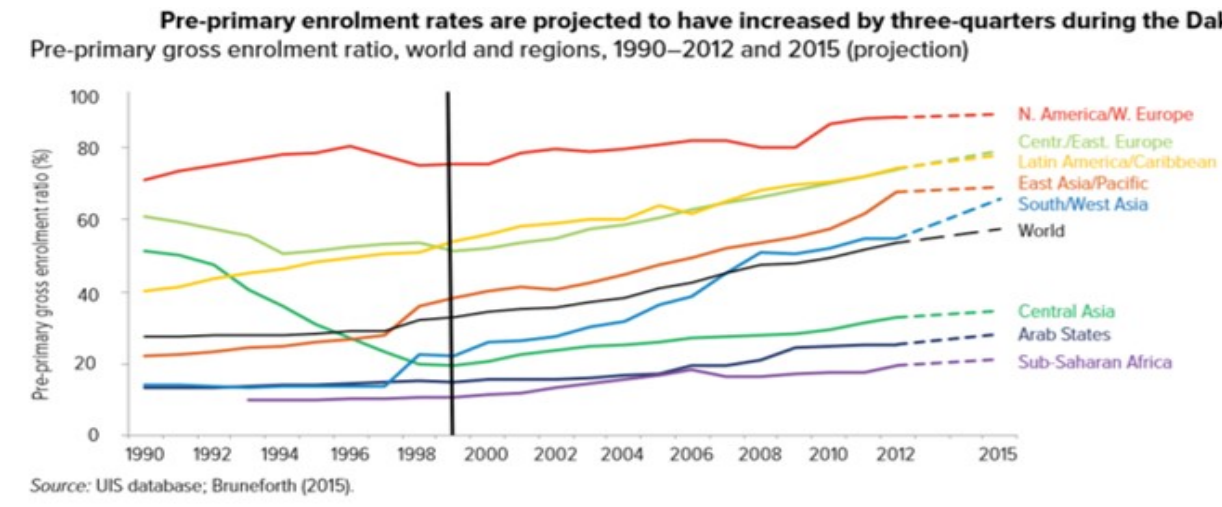

Source: UNESCO, 2015, p.5. 
Also reported empirical research from the United States and the United Kingdom, findings in low-and middle-income countries often indicate the important beneficial impact on pre-primary education:

Approximately one year of pre-primary education in Argentina culminated in an overall 8 per cent rise in grade 3 language and mathematics grades and had beneficial results on non-cognitive behavioral skills.

In Bangladesh, infants in a high-quality pre-school curriculum outperformed the test group in verbal and non-verbal thinking and school preparation.

In Mozambique, relative to the control community, infants in the rural nursery were 24 per cent more likely to participate in primary school and demonstrated increased academic ability, fine motor skills and results.
Enrolment in pre-primary education around the world

According to the Education for All (EFA) Global Monitoring Report (2015), enrolment in pre-primary education has risen by almost two-thirds (to 180 million) in the last decade. Although it is encouraging to see that the gross enrolment rate increased from $32.8 \%$ in 1999 to $53.7 \%$ in 2012 , only a tiny percentage of children $17 \%$ in low-income countries had access in 2012. These statistics also mask significant regional disparities. Among low-and middle-income countries, Latin America and the Caribbean (LAC) have the highest participation rate $(74.5 \%)$, while sub-Saharan Africa has the lowest participation rate (19.5\%).South and West Asia and East Asia and the Pacific have made the most progress in enrolling students in pre-primary in recent years.

The graph below (Figure 2) shows a different african sub continent country's expansion ratio of gross enrollment in preprimary schools between 1999 and 2012.

Figure 2: Pre-primary Gross Enrolment Ratio in different Countries

In all but a few countries, the pre-primary gross enrolment ratio rose between 1999 and 2012

Pre-primary education gross enrolment ratio, 1990 and 2012

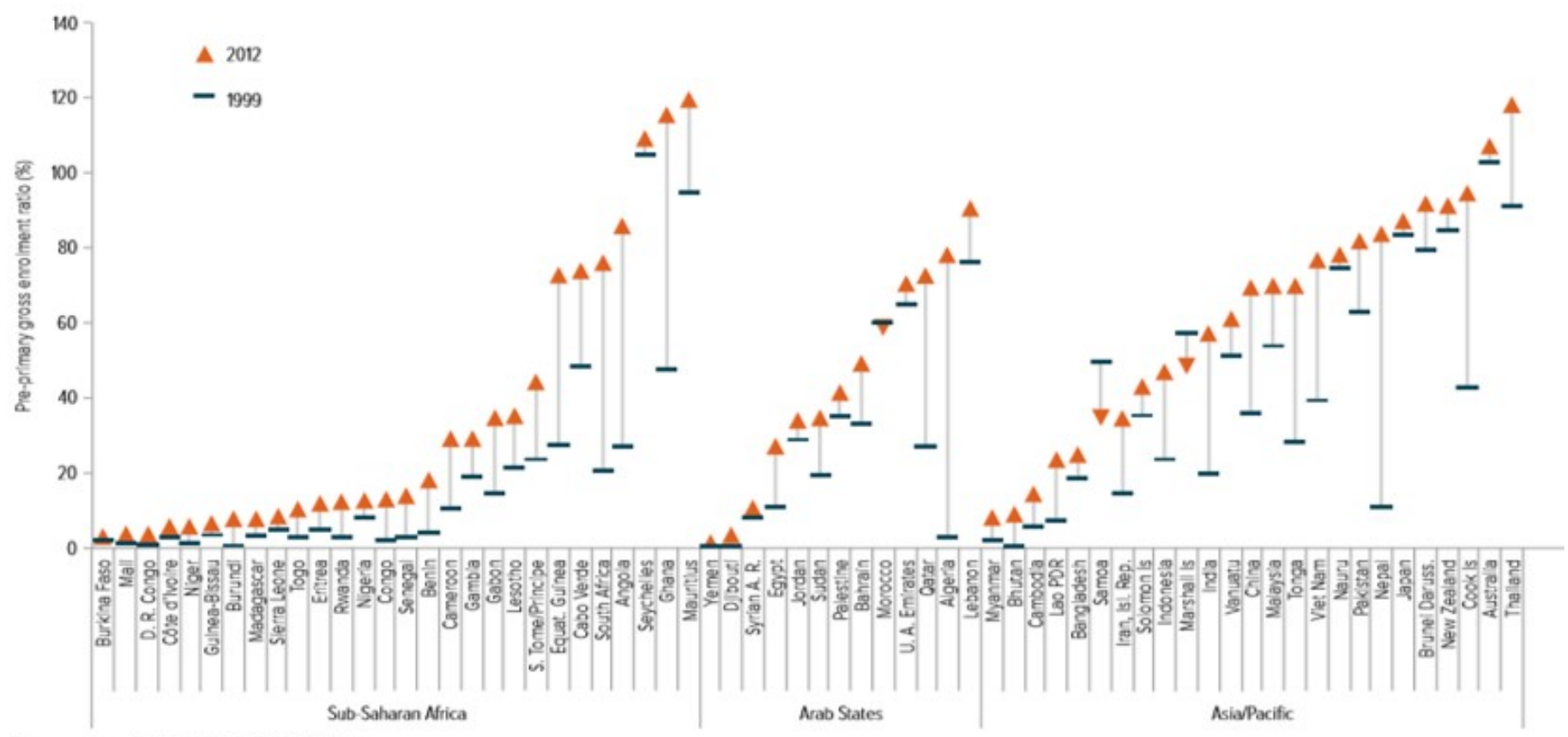

Sources: Annex, Statistical Table 3B; UIS database

Source: UNESCO, 2015, p.60.

These comparative findings in the graph help each country understand the role's gross status and learn from each other. They will take insights and perspectives from each other to improve their pre-primary education program. This is a detailed illustration of how a comparative education method will lead to each other's education systems.
The graph below (Figure 3) shows the distribution of time spent by children in pre-primary schools in different countries. This graph provides information and understanding of how children in pre-primary schools in Bangladesh spend time with other countries worldwide. 
Figure 3: Distribution of Time the Children spend pre-primary schools in different Countries

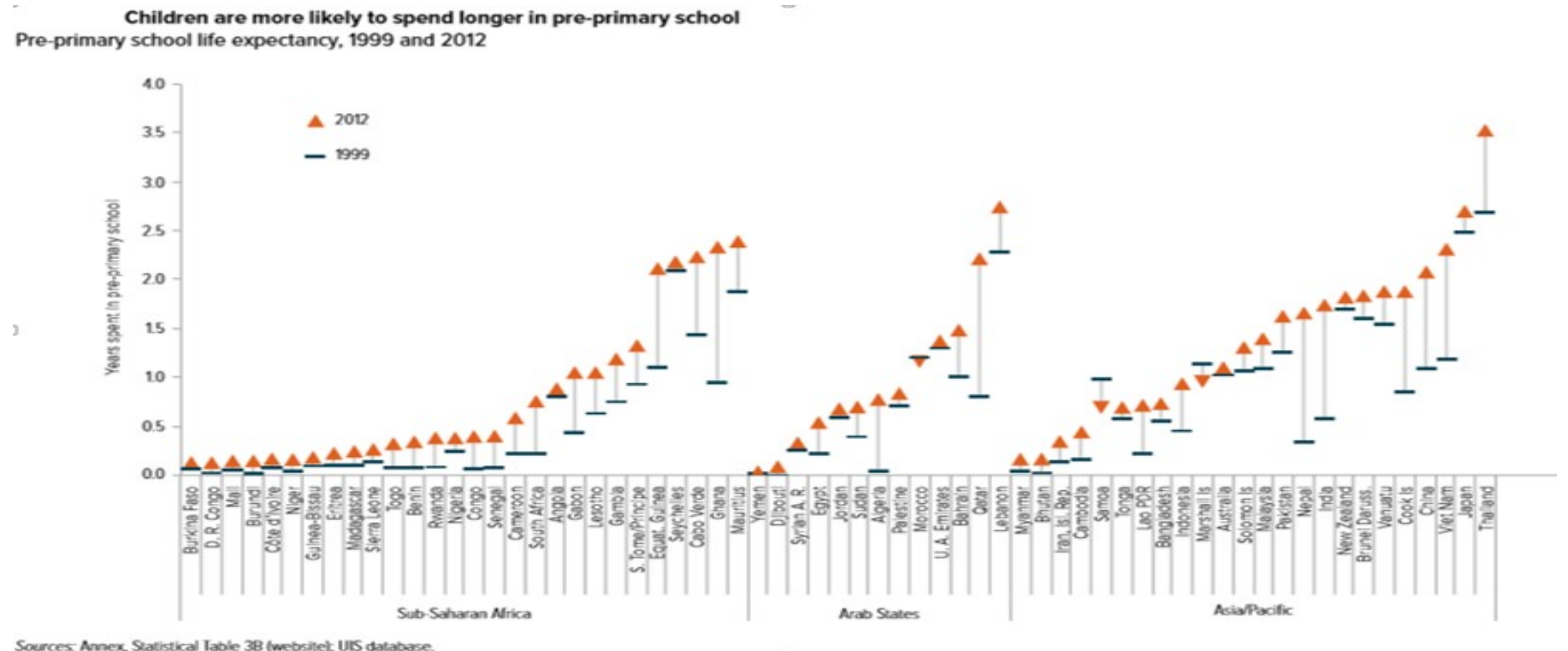

Source: UNESCO, 2015, p.60.

This comparison graph in different countries certainly shows a comparative overview of what the government of Bangladesh can do to improve its existing practice of pre-primary education.

\section{Budget in Pre-primary Education: Lessons from Other Countries}

As a percentage of government spending, expenditure on education has improved little since 1999. In 2012, the world average was $13.7 \%$, dropping short of the goal of $15 \%$ to $20 \%$. Sub-Saharan Africa is where governments have dedicated the highest median share of government budgets on education (18.4\%), led by East Asia and the Pacific (17.5\%). Just 12.6 per cent is assigned to South and West Asia (Table 8.1 ). Of the 129 countries with data, 53 spent $15 \%$ or more of the total government expenditure on education in 2012, of which 12 were low income and 17 are poorer middle income countries.Of the 53 countries that spent 15 per cent or more of the total government expenditure on education, 20 spent $20 \%$ or more; of the 15 with comparable data for 1999 and 2012, 8 - including Ethiopia and Niger - started to spend less than $20 \%$ in 1999 , but were allocated $20 \%$ or more by 2012 .

A limited proportion of education budgets were dedicated to pre-primary Education in Bangladesh. As a percentage of overall policy spending on schooling, global median spending on pre-primary education contributed to just $4.9 \%$ in 2012 . North America and Western Europe allocated $8.8 \%$ of education budgets to pre-primary education, while subSaharan Africa spent $0.3 \%$ onpre-primary education. Of the 51 countries with accessible data in 1999 and 2012, 37 raised public spending on pre-primary education as a GDP share over the period. Disaggregated by income, the differences are significant.In the 22 high-income nations, 18 boosted the preprimary share in school budgets. Of the nine low and low middle-income countries, five - including Benin, the Plurinational State of Bolivia and the United Republic of Tanzania - increased their share.

\section{How Comparative Education Research helps Bangladesh to improve its current practice of Pre-Primary Education}

The Government of Bangladesh can benefit from the lessons learned from the findings of comparative education research. A detailed, comprehensive and comprehensive comparative education research can certainly provide multi-faceted opportunities to be considered in promoting existing policies, practices, procedures and processes in the context of preprimary Education in Bangladesh. Any of the essentialfindings to comparative education work on the preprimary educational cycle can be described as follows:

As comparative education includes researching education from a viewpoint where situations, primarily global, are linked to one another;thus, in this case, Bangladesh's government can consider the realities of pre-primary education by contrasting circumstances in other countries.

Observations in comparative education research help each other understand the nature of the different education systems that exist in a wide range of contexts around the world. Here, Bangladesh's pre-primary education strategy will be acquainted with the pre-primary education processes implemented in various regional settings and take sufficient time to know about specific facets of education followed by others.

Comparative education often referred to as comparativeand foreign Education (CIE), has been conceptualised as a multidisciplinary endeavour spanning local and global expertise, integrating science philosophy and information specific and specialised. Lessons learned from the results of 
comparative education study The Government of Bangladesh, thus, agree on possible measures to help implement its preprimary education to reach the required level of achievement.Through comparative education research, the government of Bangladesh can improve pre-primary education and set a standard that can be established based on pre-primary experience worldwide. It can certainly lead to a further drive to ensure the quality of pre-primary education, taking into account international perspectives.

During comparative education research, Bangladesh's government will study its current pre-primary education policies and procedures and align them with international trends. It can increase its acceptance of its policy and practice to be established by pre-primary scholars and open the window to provide enriched lessons for others to follow.

Bangladeshi's government can review its existing pre-primary education policies and procedures and align with international trends through comparative education research. It can increase its acceptance of its policy and practice to be established by pre-primary scholars and open the window to provide enriched lessons for others to follow.

\section{IV.CONCLUSION}

Comparative learning is highly viewed as an interdisciplinary macro-field of education. It draws on the different disciplines of the social sciences for its theoretical and methodological resources. Comparative education research is carried out intensively to study cross-societal issues or education systems properly. Using the above analysis on pre-primary Education in Bangladesh and other countries, the Government of Bangladesh receives broader experience and learning from other countries that improve its pre-primary education system.

\section{REFERENCES}

[1] Barnett, W.S. (2008). Preschool education and it's lasting effects: Research and policy implications. National Institute for Early Education Research Rutgers, The State University of New Jersey.

[2] Berlinski, S.; Galiani, S.; \&Gertler, P., (2006), The effect of preprimary education on primary school performance. The Institute of Fiscal Studies, London, UK, Retrieved on 23/05/2018 fromhttps://www.ifs.org.uk/wps/wp0604.pdf

[3] Bray, M., Adamson, B., \& Mason, M. (Eds.). (2007).Comparative education research: Approaches and methods. Comparative Education Research Centre; Springer Science + Business Media. https://doi.org/10.1007/978-1-4020-6189-9

[4] Crossley, M., and Watson, K., (2003), Comparative and International Research in Education Globalisation, context and difference. London and New York: RoutledgeFalmer.

[5] Daka, H., Chipindi, F.M. \& Mwale-Mkandawire, M. (2020). The relationship between assessment practices and students' academic performances. A case of undergraduate students at the medical school of the university of Zambia, 2008 - 2016. Zambian Journal of Educational Management, Administration and Leadership, 1, (1), 143-156. ISSN: 2706-7416 (Print).
[6] DPE (2015), Annual Primary School Census - 2015, DPE, MoPME Retrieved on 18/05/2018 from: http://dpe.portal.gov.bd/sites/default/files/files/dpe.portal.gov.bd/p ublications/f2501e16 4f57 467b 8c67 48a5855f88fe/Final\%20D raft\%20APSC2015.pdf

[7] DPEd (2013), Primary Teacher Education, DPEd Professional Education, Diploma in Primary Education, National Academy for Primary Education (NAPE), Mymensingh, Bangladesh

[8] Education Watch, (2013), New Vision Old Challenges: The State of Pre-primary Education in Bangladesh, CAMPE Campaign for Popular Education, Dhaka, Bangladesh

[9] FNBE_ Finnish National Board of Education (2010), National Core Curriculum for Pre-primary Education 2010, Finnish National Agency for Education, Finland, Retrieve on 10/06/2018 from:http://www.oph.fi/download/153504_national_core_curricul um_for_pre-primary_education_2010.pdf

[10] Graham, J., (2017), The Unprecedented Rise of Pre primary Education in Bangladesh, London, UK, Retrieve on 23/06/2018 from: https://apolitical.co/solution_article/unprecedented-rise-preprimary-education-bangladesh/

[11] Haque, M.; Nasrin, S.; Yesmin, M. N. and Biswas, M. H. A., (2013), Universal Pre-Primary Education: A Comparative Study, American Journal of Educational Research, 2013, Vol. 1, No.1,3136; Retrieveon23/06/2018from:https://pdfs.semanticscholar .org/c981/be80b6005b01631fc84a0c662b69ee7d1cf9.pdf

[12] Jahan, M. (2002).Early childhood care, Education and Development (ECCED) in Bangladesh, Bangladesh Education Journal, Vol-1, 1-24Elephant Road ,Katabon, Dhaka-1205.

[13] Kaul, V., (2002) Early Childhood Care and Education In: R Govinda (ed.) (2002) India Education Report New Delhi: Oxford University Press.

[14] MoE_Ministry of Education (2010), National Education Policy 2010, Ministry of Education, Government of People's Republic of Bangladesh, Dhaka: Bangladesh

[15] Osborn, D.; Cutter, A. \&Ullah, F., (2015), Universal Sustainable Development Goals: Understanding the Transformational Challenges for Developed Countries, Stakeholder Forum,Retrieveon01 January2018from:https://sustainabledevelopm ent.un.org/content/documents/1684SF_SDG_Universality_Report_-_May_2015.pdf

[16] Patricia Broadfoot, (2000), Comparative Education for the TwentyFirst Century: retrospect and prospect. Comparative Education Vol. 36, No. 3, pp.357-371.

[17] Rashid, F., (2015), Exploring 'Individualised Teaching'in a Government Pre-primary Classroom in Bangladesh, Retrieve on 24/05/2018 from: https://bdeduarticle.com/exploringindividualized-teaching-in-a-government-pre-primary-classroomin-bangladesh/

[18] Thomas, M. A.M., Serenje-Chipindi, J \& Chipindi, F.M. (2020), Comparing course syllabi from A to Z: Examining the contexts, content, and concerns for social foundations of education in Australia and Zambia. In A. E. Mazawi \& M. Stack (Eds.). Course syllabi in faculties of education across the world: Bodies of knowledge and their discontents (pp 38-50). Sydney: Bloomsbury, ISBN 978-1-3500-9425-3 (hardback) 978-1-35009427-7 (online).

[19] UNESCO, (2006), Pre-Primary Education: A Valid Investment Option for EFA, Section for Early Childhood and Inclusive Education, UNESCO, France, Retrieve on 23/05/2018 from: http://unesdoc.unesco.org/images/0014/001439/143986e.pdf

[20] UNESCO, (2015), Education for All (EFA) Global Monitoring Report_2015, ISBN 978-92-3-100085-0, UNESCO: France.Retrieve on 23/05/2018 from: unesdoc.unesco.org/images/0023/002322/232205e.pdf 